\title{
Infants hospitalized for Bordetella pertussis infection commonly have respiratory viral coinfections
}

\author{
A. Frassanito ${ }^{1}$, R. Nenna ${ }^{1}$, A. Nicolai ${ }^{1}$, A. Pierangeli ${ }^{2}$, A. E. Tozzi ${ }^{3}$, P. Stefanelli ${ }^{4}$, R. Carsetti ${ }^{5}$, C. Concato ${ }^{6}$, I. Schiavoni ${ }^{4}$, \\ F. Midulla ${ }^{1 *}$ and the Pertussis study group
}

\begin{abstract}
Background: Whether viral coinfections cause more severe disease than Bordetella pertussis (B. pertussis) alone remains unclear. We compared clinical disease severity and sought clinical and demographic differences between infants with $B$. pertussis infection alone and those with respiratory viral coinfections. We also analyzed how respiratory infections were distributed during the 2 years study.

Methods: We enrolled 53 infants with pertussis younger than 180 days (median age 58 days, range 17-109 days, 64. $1 \%$ boys), hospitalized in the Pediatric Departments at "Sapienza" University Rome and Bambino Gesù Children's Hospital from August 2012 to November 2014. We tested in naso-pharyngeal washings B. pertussis and 14 respiratory viruses with real-time reverse-transcriptase-polymerase chain reaction. Clinical data were obtained from hospital records and demographic characteristics collected using a structured questionnaire.
\end{abstract}

Results: 28/53 infants had B. pertussis alone and 25 viral coinfection: 10 human rhinovirus ( 9 alone and 1 in coinfection with parainfluenza virus), 3 human coronavirus, 2 respiratory syncytial virus. No differences were observed in clinical disease severity between infants with $B$. pertussis infection alone and those with coinfections. Infants with B. pertussis alone were younger than infants with coinfections, and less often breastfeed at admission.

Conclusions: In this descriptive study, no associations between clinical severity and pertussis with or without co-infections were found.

Trial registration: Policlinico Umberto I: protocol 213/14, 3085/13.02.2014, retrospectively registered. Bambino Gesù Children's Hospital: protocol n. RF-2010-2317709.

Keywords: Pertussis, Respiratory virus, Severity, Child

\section{Background}

Pertussis (whooping cough) is a highly contagious, respiratory disease caused by Bordetella pertussis (B. pertussis). The clinical symptoms of pertussis change with age, previous exposure to $B$. pertussis and immunization status. In newborns clinical manifestations may be severe. Most infants have a typical paroxysmal cough which can last more than two months [1].

Pertussis is a major cause of morbidity worldwide and of mortality in infants in developing countries. Pertussis

\footnotetext{
*Correspondence: midulla@uniroma1.it

'Department of Pediatrics, "Sapienza" University of Rome, V.le Regina Elena

324, 00161 Rome, Italy

Full list of author information is available at the end of the article
}

continues as a public health concern threat given its re-emergence despite high vaccination coverage [2]. Epidemic cycles reoccur every 2 to 5 years and 2015 has witnessed the worst outbreak in the past 70 years [3].

Although ample evidence confirms coinfections between B. pertussis and other pathogens, especially viruses, the role of coinfections remains debated [4-6]. Most mixed infections probably arise accidentally and whether they cause more severe disease than $B$. pertussis alone remains unclear [7-14]. Extending current knowledge on virus coinfections would make it easier to care for infants with pertussis.

We designed this study to compare clinical disease severity in infants with $B$. pertussis infection alone and 
those with $B$. pertussis and viral coinfections hospitalized in two Italian centers over two years. We also analyzed how respiratory infections and pertussis cases were distributed during the two years study. As primary outcome measures we assigned each infant a clinical severity score and assessed length of hospitalization. As an experimental approach to provide reliable data on lower respiratory virus infections we used an extended respiratory virus panel that can detect 14 respiratory viral targets with real-time reverse-transcriptase-polymerase chain reaction (RT-PCR) assay.

\section{Methods}

\section{Patients}

In a longitudinal double-center study, we enrolled 53 consecutive infants with pertussis younger than 180 days hospitalized from August 2012 to November 2014 at the Pediatric Departments "Sapienza" University and Bambino Gesù Children's Hospital Rome. Eligible children had to have a nasopharyngeal specimen that tested positive for $B$. pertussis, be younger than 180 days, be unvaccinated against pertussis and have at least one of the following symptoms: cough lasting more than 5 days, paroxysmal cough, apnea or cyanosis and post-cough vomit.

At admission all infants underwent a nasopharyngeal washing obtained by instilling $3 \mathrm{ml}$ of sterile saline into each nostril and collected with a syringe. All samples were delivered within two hours to the Department of Infectious, Parasitic \& Immune-mediated Diseases at the Istituto Superiore di Sanità (Rome) for B. pertussis detection and to the Molecular Medicine Department ("Sapienza" University Rome Virology Laboratory) for virus detection. We considered children with $B$. pertussis infection, those with PCR positive results.

As primary outcome measures, we calculated at admission a clinical score and days of hospitalization. The clinical severity score ranged from 0 to 8 , according to respiratory rate $(<45 / \mathrm{min}=0,45-59 / \mathrm{min}=1,>60 /$ $\min =2)$, arterial oxygen saturation in room air $(>95 \%=0$, $90-94 \%=1,<90 \%=2$ ), retractions (none $=0$, present $=1$, present + nasal flare $=2$ ) and food intake requirement (normal $=0$, reduced $=1$, intravenous fluid $=2$ ), as previously described [10]. Children's parents were administered a structured questionnaire seeking demographic data. Demographic variables evaluated included gender, age at admission (in days), gestational age, birth weight, type of delivery, breastfeeding history, presence of siblings, number of cohabitants, presence of smoking cohabitants and cohabitants with concomitant respiratory symptoms. As secondary outcome measures, we searched the clinical records for data on the following clinical variables: heart rate, respiratory rate, arterial oxygen saturation in room air, retractions, oxygen-therapy, fluid therapy, episodes of paroxysmal cough, cyanosis, apnea, post-cough vomit, fever (body temperature $>37.5^{\circ} \mathrm{C}$ ), presence of skin petechiae, conjunctival hemorrhage and complications (hypoxia, bradycardia, pneumonia, gastroenteritis, thrombocytopenia, urinary tract infection, anemia, dehydration, feeding difficulties, transient hypertension). Laboratory variables investigated were white blood-cell count (WBC), lymphocyte count and C-reactive protein (CRP). A chest X-ray (CXR) obtained at hospitalization was evaluated blindly by a radiologist for consolidations.

Before infants were enrolled, all children's parents agreed and gave written informed consent to participate in the study, which was approved by institutional review boards at both hospitals (Policlinico Umberto I: protocol 213/14, 3085/13.02.2014; Bambino Gesù Children's Hospital: protocol n. RF-2010-2317709).

\section{Bordetella pertussis detection by RT-PCR and culture}

B. pertussis DNA was extracted with QIAamp DNA minikit (QiaGEM, Hilden, Germania) and amplified with the "Bordetella Real-Time PCR" kit (Diagenode Diagnostics,

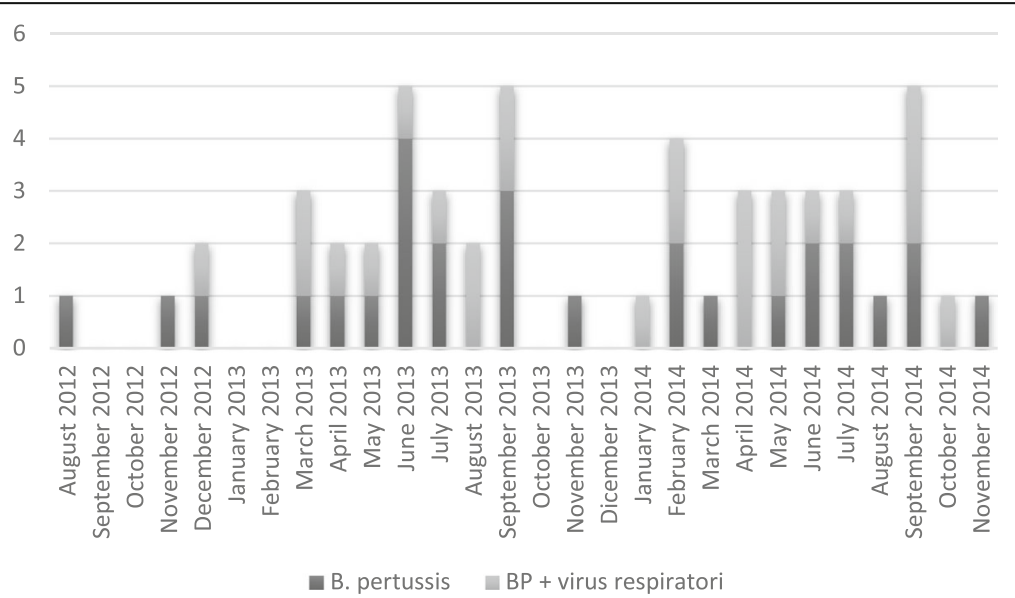

Fig. 1 Monthly Distribution of the 53 Cases of Bordetella pertussis Infection Through the 2-Year Study 
Table 1 Days Hospitalization and Clinical Severity Scores in the Two Study Groups

\begin{tabular}{llll}
\hline Variables used to score clinical severity & $\begin{array}{l}\text { Pertussis } \\
(N=28 \text { infants })\end{array}$ & $\begin{array}{l}\text { Pertussis + Virus } \\
(N=25 \text { infants })\end{array}$ & $\begin{array}{c}P \text { Values } \\
\text { Hospitalization stay in days }\end{array}$ \\
Severity score median (range) & $7(1-41)$ & $1(0-36)$ & $0.532^{*}$ \\
Heart rate in beats per minute median (range) & $1(0-7)$ & $140(120-175)$ & $0.279^{\dagger}$ \\
Respiratory rate in breaths per minute median (range) & $145(100-175)$ & $37(27-60)$ & $0.235^{\dagger}$ \\
Oxygen saturation median (range) & $39(27-70)$ & $98 \%(82-100 \%)$ & $0.702^{\dagger}$ \\
Retractions & $99 \%(85-100 \%)$ & $4 / 22(18.1 \%)$ & $0.524^{\dagger}$ \\
Oxygen-therapy & $7 / 23(30.4 \%)$ & $6 / 22(27.3 \%)$ & $0.602^{*}$ \\
Fluid therapy & $8 / 23(34.8 \%)$ & $2 / 22(9.1 \%)$ & $0.413^{*}$ \\
\hline
\end{tabular}

${ }^{*}$ by $\mathrm{X}$-square test, ${ }^{+}$by Mann-Whitney test

Liège, Belgio). The assay gave binary results. For RT-PCR the SYBR Green Detection assay we used the LightCycler 2.0 system (Roche Diagnostic). Data were analyzed with LightCycler software (version 4.0, Roche Diagnostic). Only the positive samples for $B$. pertussis were cultured on charcoal agar plates (Oxoid England) containing defibrinated sheep blood at $10 \%$ and incubated at $35{ }^{\circ} \mathrm{C}$ up to 7 days and inspected daily, as previously described [13].

\section{Respiratory virus detection}

Nasal washings were centrifuged to remove the mucus present in the sample and an aliquot was used for nucleic acid extraction using a total nucleic acid isolation kit (Roche Diagnostics, Mannheim, Germany) and an RTPCR panel that sought 14 respiratory viruses: influenza virus $\mathrm{A}$ and $\mathrm{B}(\mathrm{IV}-\mathrm{A} / \mathrm{B})$, human coronavirus (hCoV) OC43, 229E, NL-63, HUK1, adenovirus (AV), parainfluenza virus 1-3 (PIV 1-3), human-metapneumovirus (hMPV), human-bocavirus (hBoV), respiratory syncytial virus (RSV) and human rhinovirus (hRV), as previously described [10].

\section{Statistical analysis}

Statistical significance was analyzed with SPSS version 23.0 (SPSS Inc., Chicago, IL, USA). Data included percentages for discrete variables, median and range for continuous variable. Differences among groups were compared using non-parametric test for median comparison, Mann-Whitney test. The $X$-square test was applied to analyze categorical independent variables qualitatively. $P$-values $<0.05$ were considered to indicate statistical significance.

\section{Results}

Of 53 hospitalized infants (median age 58 days, range 17-109 days, 34 [64.1\%] boys) with pertussis infection enrolled, 28 (median age 51.5 days, range 17-102 days, 17 boys) had $B$. pertussis alone and 25 (median age 62 days, range $22-109$ days, 17 boys) had viral coinfections. Among 25 patients with a coinfection, 9 were coinfected with hRV, 3 with hCoV, 2 with RSV, 2 with influenza virus (1 IVA and 1 IVB), 1 with PIV, 1 with $\mathrm{AV}, 1$ with hMPV, 1 with $\mathrm{hBoV}$ and 5 patients had multivirus coinfections. Of these 53 patients, 3 had a

Table 2 Demographic Variables in the Two Study Groups

\begin{tabular}{|c|c|c|c|}
\hline Demographic variables & $\begin{array}{l}\text { Pertussis } \\
(N=28)\end{array}$ & $\begin{array}{l}\text { Pertussis + Virus } \\
(N=25)\end{array}$ & $P$ Values \\
\hline Boys & $17(60.7 \%)$ & $17(68 \%)$ & $0.396^{*}$ \\
\hline Median age at hospitalization in days (range) & $51.5(17-102)$ & $62(22-109)$ & $0.044^{\dagger}$ \\
\hline Gestational age in weeks (range) & $39(35-41)$ & $39(37-41)$ & $0.105^{\dagger}$ \\
\hline Birth weight in $\mathrm{Kg}$ (range) & $3.345(1.940-4.450)$ & $3.250(2.500-4.100)$ & $0.618^{\dagger}$ \\
\hline Cesarean section & $10(35.7 \%)$ & $8(32 \%)$ & $0.503^{*}$ \\
\hline Breastfeeding at recovery & $13(46.4 \%)$ & 19 (76\%) & $0.048^{*}$ \\
\hline Months breastfeeding & $1.02(0-2.14)$ & $1.91(0.27-3.58)$ & $0.004^{\dagger}$ \\
\hline Presence of siblings & $16(57.1 \%)$ & $19(76 \%)$ & $0.123^{*}$ \\
\hline Number of cohabitants $\geq 4$ & $19(67.9 \%)$ & $22(88 \%)$ & $0.076^{*}$ \\
\hline Passive smoke & $10(35.7 \%)$ & $11(44 \%)$ & $0.798^{*}$ \\
\hline Co-habitants with respiratory symptoms & $21(75 \%)$ & 22 (88\%) & $0.197^{*}$ \\
\hline
\end{tabular}

"by $\mathrm{X}$-square test, ${ }^{\dagger}$ by Mann-Whitney test 
Table 3 Clinical differences in the Two Study Groups

\begin{tabular}{llll}
\hline Clinical variables & $\begin{array}{l}\text { Pertussis } \\
(N=28)\end{array}$ & \multicolumn{1}{l}{$\begin{array}{l}\text { Pertussis }+ \text { Virus }^{(N=25)} \\
\text { Duration of symptoms before hospitalization (mean } \pm \text { SD) }\end{array}$} \\
Paroxysmal cough & $11.4 \pm 7.8$ & $13.1 \pm 9.9$ & $19(76 \%)$ \\
Cyanosis & $24(85.7 \%)$ & $14(56 \%)$ & 0.515 \\
Apnea & $16(57.1 \%)$ & $20(80 \%)$ & 0.291 \\
Post-cough vomit & $24(85.9 \%)$ & $14(56 \%)$ & 0.425 \\
Fever: $T>37.5^{\circ} \mathrm{C}$ & $15(57.6 \%)$ & $5(20 \%)$ & 0.540 \\
Skin petechiae & $3(10.7 \%)$ & $4(16 \%)$ & 0.288 \\
Conjunctival hemorrhage $^{*}$ & $1(3.6 \%)$ & $3(12 \%)$ & 0.142 \\
Complications $^{\mathrm{a}}$ & 0 & $6(24 \%)$ & 0.098 \\
\hline
\end{tabular}

*by $\mathrm{X}$-square test

ahypoxia, bradycardia, pneumonia, gastroenteritis, thrombocytopenia, urinary tract infection, anemia, dehydration, feeding difficulties, transient hypertension

gestational age lower than 37 weeks. A total of 4 children (3 Pertussis alone and 1 coinfected) required pediatric intensive care admission.

During the 2-year study $B$. pertussis infection alone was detected mainly during the summer whereas coinfections were equally distributed throughout the year (Fig. 1).

Clinical severity score and days hospitalization were similar in children with $B$. pertussis infection alone and those with $B$. pertussis and viral coinfection (Table 1).

The questionnaire indicated that infants with $B$. pertussis alone were younger than infants with coinfections ( $p=0.044$ by Mann-Whitney test). Questionnaire answers also showed that infants with $B$. pertussis alone were less often breastfeed at admission than infants with coinfections ( $p=0.048$ by $X$-square test) and for a shorter time ( $p=0.004$ by Mann-Whitney test). Finally, infants with coinfections more frequently had a higher number of cohabitants though not significantly ( $p=0.076$ by $x$-square test).

The two groups had no significant differences for other demographic, clinical, laboratory and radiological data (Tables 2, 3 and 4).

\section{Discussion}

In this descriptive study investigating the clinical data for 53 infants younger than 180 days hospitalized with pertussis, no associations between clinical severity and pertussis with or without co-infections were found.

As many as $25 / 53$ (47\%) of the infants hospitalized with pertussis over the two years were coinfected with other respiratory viruses. A distinctive point is that because we analyzed a wide virus battery and did so in infants hospitalized continuously in two centers over two years we feel confident that our study provides reliable data on the distribution of respiratory infections. Few studies found $B$. pertussis cases in infants with respiratory pathogens. For example, Piedra et al., identified by RT-PCR only 4 B. pertussis cases in 2068 patients with respiratory pathogens and all these infants were younger than 6 months. In 3 of the 4 infants with $B$. pertussis RT-PCR identified a second respiratory pathogen: 2 had an hRV and 1 child an hCoV coinfection [8]. In a similar study, Korppi et al., showed in a nasopharyngeal aspirate by RT-PCR $B$. pertussis infection in 7 on 9 of patients hospitalized for RSV infection [15]. Our lower percentage of coinfections reflects the analysis of a larger series of children with $B$. pertussis than the other two studies.

As well as extending current epidemiological knowledge on respiratory pathogens, we confirmed that pertussis in Italy arises mainly during the summer months, whereas respiratory virus coinfections are equally distributed over the year [10]. Virological analysis showed that the most

Table 4 Laboratory and Radiological Variables in the Two Study Groups

\begin{tabular}{|c|c|c|c|}
\hline Laboratory and radiological variables & $\begin{array}{l}\text { Pertussis } \\
(N=28)\end{array}$ & $\begin{array}{l}\text { Pertussis + Virus } \\
(N=25)\end{array}$ & $P$ Values \\
\hline White blood cells $\left(\times 10^{3}\right.$ cells $/ \mu$ l) median (range) & $15.38(2.31-37.48)$ & $17.04(5.69-40.84)$ & $0.110^{\dagger}$ \\
\hline Lymphocytes $\left(\times 10^{3}\right.$ cells $\left./ \mu \mathrm{l}\right)$ median (range) & $8.31(0.1-17.88)$ & $6.89(0.74-35.42)$ & $0.272^{\dagger}$ \\
\hline WBC\% Lymphocytes median (range) & $61.9 \%(31.3-81.6 \%)$ & $61 \%(19.3-80.1 \%)$ & $0.427^{\dagger}$ \\
\hline C-reactive protein (mg/dL) median (range) & $0.05(0-3.6)$ & $0.05(0.03-5.06)$ & $0.461^{\dagger}$ \\
\hline Consolidations on chest X-ray & 4/16 (25\%) & $0 / 12$ & $0.084^{*}$ \\
\hline
\end{tabular}

"by $\mathrm{X}$-square test, tby Mann-Whitney test 
frequent virus observed was hRV (36\%) and only 2 infants had RSV (8\%). We presume that the distribution of coinfections reflects the observation that hRV epidemiology maintains a steady epidemic curve throughout the year and hRV can be detected also in asymptomatic children. In fact in a Netherlands study conducted in recent years Wildenbeest JG et al., found hRV in $25 \%$ of asymptomatic children [16].

A new finding in this study is the lack of differences in clinical disease severity (measured as clinical severity score and days hospitalization) in infants with B. pertussis infection alone and those with coinfections. Although no other published studies have tested 14 respiratory viruses in infants with pertussis, Nuolivirta et al., studied 142 infants aged less than 180 days hospitalized for bronchiolitis who underwent a nasopharyngeal aspirate to detect only 7 respiratory viruses and $B$. pertussis by RT-PCR. B. Pertussis involvement was found in 12 of 142 (8.5\%) infants hospitalized for bronchiolitis and, of these, 8 were in coinfection with RSV. They found no differences in clinical findings, days hospitalization and breastfeeding at admission in patients with respiratory viruses alone than in patients with respiratory viruses in coinfections with B. pertussis [17]. Schnoeller et al. showed that respiratory infection of neonatal mice with an attenuated $B$. pertussis can protect against RSVinduced disease in adult life $[18,19]$. In a human model Schiavoni et al. demonstrated that an attenuated $B$. pertussis rescues the immune functions of RSV infected human dendritic cells by promoting a protective Th1/ Th17 responses. Self-limiting respiratory infections with attenuated bacteria or commensal microbes may have a beneficial effect limiting potentially lethal diseases caused by respiratory viruses in infants [20].

When we evaluated the secondary endpoints in our study, infants with $B$. pertussis alone were younger, less often breastfeed and breastfeed for a shorter time than infants with coinfections. Similarly, in a previous study from our group, comparing infants with $B$. pertussis and those with bronchiolitis, we found that the percentage of breastfed infants at hospitalization was lower in infants with B. pertussis than in those with RSV bronchiolitis [13]. This finding is difficult to explain. We always strongly encourage breastfeeding in infants because it has well-known immunological and nutritional advantages [21]. In a recent large multicenter study, on pertussisassociated pneumonia in children from low- and middleincome countries, pertussis-positive cases were more likely to have never been breastfed compared with controls [22]. Our finding might reflect mother-to-child transmission of respiratory infections during breastfeeding.

Our study has limitations: small sample size and our failure to compare B. pertussis infection with viral coinfections by single respiratory viruses.

\section{Conclusions}

In conclusion, about one third of infants with $B$. pertussis may have a respiratory viral coinfection. These undetected coinfections seem to leave the clinical severity of pertussis in infants unchanged.

\begin{abstract}
Abbreviations
AV: Adenovirus; B. Pertussis: Bordetella Pertussis; CRP: C-reactive protein; CXR: Chest X-ray; hBoV: Human-bocavirus; hCoV OC43, 229E, NL-63, HUK1: Human coronavirus OC43, 229E, NL-63, HUK1; hMPV: Humanmetapneumovirus; hRV: Human rhinovirus; IV -A/B: Influenza virus A and B; PIV 1-3: Parainfluenza 1-3; RSV: Respiratory syncytial virus; RT-PCR: Real-time reverse-transcriptase-polymerase chain reaction; T: Temperature; WBC: White blood cell
\end{abstract}

\section{Acknowledgements}

We acknowledge the Pertussis study group: Greta Di Mattia (Department of Pediatrics, "Sapienza" University of Rome, Rome, Italy); Elisabetta Pandolfi, Francesco Gesualdo, Eleonora Agricola, Luisa Russo, Beatrice Ferretti, Ilaria Campagna (Multifactorial Disease and Complex Phenotype Research Area Bambino Gesù Children's Hospital, Rome, Italy); Alberto Villani, Michaela Veronika Gonfiantini (Department of Pediatrics, Bambino Gesù Children Hospital); Valentina Marcellini (Immunology Unit, Immunology and Pharmacal Therapy Area, Bambino Gesù Children's Hospital, Rome, Italy); Valentina Spuri Vennarucci, (Virology Unit, Bambino Gesù Children's Hospital, Rome, Italy); Gabriele Buttinelli, Giorgio Fedele (Department of Infectious, Parasitic \& Immunomediated Disease, Istituto Superiore di Sanità, Rome, Italy).

\section{Funding}

This work was supported by Grants from the Italian Ministry of Health, RF-2010-2317709.

\section{Availability of data and materials}

The datasets used and analysed during the current study are available from the corresponding author on reasonable request.

\section{Authors' contributions}

AF participated in the design of the study, performed the statistical analysis and wrote the paper. RN participated in the design and coordination of the study, helped to draft the manuscript and participated to the statistical analysis. AN collected samples. AP carried out the virological analysis and helped to draft the manuscript. AET participated in the design and coordination of the study and revised the final version. PS carried out the molecular genetic analysis. RC collected samples. CC carried out the virological analysis. IS carried out the acquisition and participated to the statistical analysis. FM conceived of the study and participated in its design, helped to draft the manuscript and revised the final version. All the authors read and approve the final manuscript.

\section{Ethics approval and consent to participate}

Before infants were enrolled, all children's parents agreed and gave written informed consent to participate in the study, which was approved by institutional review boards at both hospitals (Policlinico Umberto I: protocol 213/14, 3085/13.02.2014; Bambino Gesù Children's Hospital: protocol n. RF2010-2317709).

\section{Consent for publication \\ Not applicable.}

\section{Competing interests}

The authors declare that they have no competing interests.

\section{Publisher's Note}

Springer Nature remains neutral with regard to jurisdictional claims in published maps and institutional affiliations.

\section{Author details}

'Department of Pediatrics, "Sapienza" University of Rome, V.le Regina Elena 324, 00161 Rome, Italy. "Molecular Medicine Department, "Sapienza" 
University of Rome, Rome, Italy. ${ }^{3}$ Multifactorial Disease and Complex Phenotype Research Area, Bambino Gesù Children's Hospital, Rome, Italy. ${ }^{4}$ Department of Infectious, Parasitic \& Immunomediated Disease, Istituto Superiore di Sanità, Rome, Italy. Immunology Unit, Immunology and

Pharmacal Therapy Area, Bambino Gesù Children's Hospital, Rome, Italy.

'Virology Unit, Bambino Gesù Children's Hospital, Rome, Italy.

Received: 5 April 2017 Accepted: 26 June 2017

Published online: 12 July 2017

\section{References}

1. Adams DA, Thomas KR, Jajosky RA, Foster L, Sharp P, Onweh DH, et al. Nationally Notifiable Infectious Conditions Group. Summary of Notifiable Infectious Diseases and Conditions - United States. MMWR Morb Mortal Wkly Rep. 2014. 2016;63(54):1-152.

2. Tozzi AE. Pandolfi E, Pastore Celentano L, Massari M, Salmaso S, Ciofi degli Atti ML et al. comparison of pertussis surveillance systems in Europe. Vaccine. 2007;25:291-7.

3. Marti M. Pertussis vaccines: WHO position paper, August 2015 Recommendations. Vaccine. 2015;34:1423-5.

4. Walsh PF, Kimmel L, Feola M, Tran T, Lim C, De Salvia L, et al. Prevalence of Bordetella pertussis and Bordetella parapertussis in infants presenting to the emergency department with bronchiolitis. J of Emergency Medicine. 2011;40:256-61.

5. Siberry GK, Paquette NR, Ross TI, Perl TM, Valsamakis A. Low prevalence of pertussis among children admitted with respiratory symptoms during respiratory syncytial virus season. Infect Control Hosp Epidemiol. 2006;27:95-7.

6. Cosnes-Lambe C, Raymond J, Chelumeau M, Pons-Catalano C, Moulin F, de Suremain N, et al. Pertussis and respiratory syncytial virus infections. Eur J Pediatr. 2008;167:1017-9.

7. Heininger U, Burckhardt MA. Bordetella pertussis and concomitant viral respiratory tract infections are rare in children with cough illness. Pediatr Infect Dis J. 2011;30:640-4.

8. Piedra PA, Mansbach JM, Jewell AM, Thakar SD, Grant CC, Sullivan AF, et al. Bordetella pertussis is an uncommon pathogen in children hospitalized with bronchiolitis during the winter season. Pediatr Infect Dis J. 2015;34:566-70.

9. Versteegh FG, Mooi-Kokenberg EA, Schellekens JF, Roord JJ. Bordetella pertussis and mixed infection. Minerva Pediatr. 2006;58:131-7.

10. Midulla F, Scagnolari C, Bonci E, Pierangeli A, Antonelli G, De Angelis D, et al. Respiratory syncytial virus, human bocavirus and rhinovirus bronchiolitis in infants. Arch Dis Child. 2010;95:35-41.

11. Samos MM, Torres AM, Pradillo Martín MC, Moreno-Pérez D, Cordón Martínez A, Urda Cardona A, et al. Incidence and severity of pertussis in infants with a respiratory syncytial virus infection. Enferm Infecc Microbiol Clin. 2015;33:476-9.

12. Moreno L, Montanaro P, Bujedo E, Cámara J, Abilar C, Terzoni M, et al. Pertussis predictors in hospitalized infants with acute lower respiratory tract infection. Rev Fac Cien Med Univ Nac Cordoba. 2013;70:63-9.

13. Nicolai A, Nenna R, Stefanelli P, Carannante A, Schiavariello C, Pierangeli A, et al. Bordetella pertussis in infants hospitalized for acute respiratory symptoms remains a concern. BMC Infect Dis. 2013;13:526.

14. Abu Raya B, Bamberger E, Kassis I, Kugelman A, Srugo I, Miron D. Bordetella pertussis infection attenuates clinical course of acute bronchiolitis. Pediatr Infect Dis J. 2013;32:619-21.

15. Korppi M, Hiltunen J. Pertussis is common in nonvaccinated infants hospitalized for respiratory syncytial virus infection. Pediatr Infect Dis J. 2007:27:316-8.

16. Wildenbeest JG, van der Schee MP, Hashimoto S, Benschop KS, Minnaar RP, Sprikkelman AB, et al. Prevalence of rhinoviruses in young children of an unselected birth cohort from the Netherlands. Clin Microbiol Infect. 2016;22(8):736.

17. Nuolivirta K, Koponen P, He Q, Halkosalo A, Korppi M, Vesikari T, et al. Bordetella pertussis infection is common in nonvaccinated infants admitted for bronchiolitis. Pediatr Infect Dis J. 2010;29:1013-5.

18. Kingston $\mathrm{HG}$, Mills BA. Prior exposure to bacteria attenuates viral disease of the respiratory tract: a role for IL-17 and innate immune memory? Am J Respir Crit Care Med. 2014;189:126-8.

19. Schnoeller C, Roux X, Sawant D, Raze D, Olszewska W, Locht C, et al. Attenuated Bordetella pertussis vaccine protects against respiratory syncytial virus disease via an IL-17-dependent mechanism. Am J Respir Crit Care Med. 2014;189(2):194-202.
20. Schiavoni I, Fedele G, Quattrini A, Bianco M, Schnoeller C, Openshaw PJ, et al. Live attenuated B. Pertussis BPZE1 rescues the immune functions of respiratory Syncytial virus infected human dendritic cells by promoting Th1/ Th17 responses. PLoS One. 2014;9(6):e100166.

21. Lanari M, Prinelli F, Adorni F, Di Santo S, Faldella G, Silvestri M, et al. Maternal milk protects infants against bronchiolitis during the first year of life. Results from an Italian cohort of newborns. Early Hum Dev. 2013;89:S51-7.

22. Barger-Kamate B, Knoll MD, Wangeci Kagucia E, Prosperi C, Baggett EC, Abdullah Brooks W, et al. Pertussis-associated pneumonia in infants and children. Pertussis-associated pneumonia in infants and children. Clin Infect Dis. 2016;63(suppl 4):S187-96.

\section{Submit your next manuscript to BioMed Central and we will help you at every step:}

- We accept pre-submission inquiries

- Our selector tool helps you to find the most relevant journal

- We provide round the clock customer support

- Convenient online submission

- Thorough peer review

- Inclusion in PubMed and all major indexing services

- Maximum visibility for your research

Submit your manuscript at www.biomedcentral.com/submit
Biomed Central 